\title{
Development of a Risk Management Process for the Construction Sector
}

\author{
Dina Alfreahat $^{1}$ and Zoltán Sebestyén ${ }^{2}$
}

1 Budapest University of Technology and Economics, Budapest, Hungary, alfreahat@mvt.bme.hu

2 Budapest University of Technology and Economics, Budapest, Hungary, sebestyen@mvt.bme.hu

\begin{abstract}
Projects are surrounded by a range of risks that can hinder their success, especially at the moment that characterized by the acceleration of economic growth, advanced technology, and intense competition. Construction projects have a special nature and one of their most important features is the project duration that may lead to changes in the conditions, which makes them contain multiple risks due to the long duration of the implementation period and the multiple stages that leads to increases in the probability of occurrence of the risks, which reflects negatively on the economics of construction. Therefore, risk management has emerged as a solution to control risks in a systematic and scientific way to avoid their negative effects.
\end{abstract}

This research aims to extend the processes of risk management from the perspective of construction to provide a framework for construction risk management processes. In this regard, the research highlighted the standard risk management processes based on PMBOK. Furthermore, we investigated the processes of construction risk management in the literature which lead to introduce two more processes besides the standard one, which are risk analysis verification and risk plan experimentation. This facilitated to develop the risk management outcomes in order to bring benefit to the organization. Additionally, we introduced some suggestions for construction risk management such as training and establishing a project risk information system in order to improve construction risk management. These suggestions shed more light on increasing the effectiveness of risk management through new ways.

(c) 2020 The Authors. Published by Budapest University of Technology and Economics \& Diamond Congress Ltd Peer-review under responsibility of the Scientific Committee of the Creative Construction Conference 2020.

Keywords: construction project, risk analysis, risk management, risk management process

\section{Introduction}

Due to the lack of proper risk management, projects usually end up with financial losses and waste of resources which, in turn, affects the credibility of the organization that has a negative impact on it is image and relations with stakeholders [1]. Therefore, it is essential for projects to implement risk management to succeed and achieve their planned results and objectives. Risk management helps to recognize the potential risks that the project may be facing and identify steps and procedures that mitigate the effects of these risks on the project and its consequences. Additionally, it develops the decision-making, planning and prioritization methods through a comprehensive and systematic understanding of project activities, the negative and opportunities available. Furthermore, it brings important benefits such as reduced cost, and increased stakeholder engagement. It was found that most construction risk management decisions have done based on previous experience, intuition. and judgment of the manager. As a result of the lack of formality of the system and the lack of integrative mechanisms of risk management among the parties involved in the project [2] [3]. The fundamental objective of integrated risk management for the construction project is to identify, manage and control risks more intelligently, and appropriately. 
Considering that the implementation of these projects must be in accordance with the approved budget, on time and within the required specifications [4].

\section{Construction risk management processes}

Construction risk management is a proactive process and a systematic approach to control and minimize risks and even prevent their effects. These steps are carried out throughout the entire project life cycle. Certain risks are within the boundaries of the project, some others lie outside the project, but still inside the organization, and there are ones outside the organization. These risks must be identified and handled at the right level, and by the proper risk owner. Here it must be emphasized that the risk owner is not the owner of the project and they have a different interpretation of risk. The Risk Owner is usually the one who can best identify and monitor the risk and that can best drive the specified countermeasures.

\subsection{Plan risk management}

It is a very important and essential process that determines the way in which the other processes will be followed and therefore the basis of their success. In this process, the risk management method must be selected along with the risk itself and predict how important it is to the stakeholders and participants. The stakeholders of the project may have a strong perspective on project risk. While some stakeholders may be risk-tolerant, others may wish to staff and structure the work to minimize extreme outcomes [5]. During this phase, the degree, the type, and the visibility of risk management are defined by the scope of the process and who are involved in it. Also, roles, responsibilities, the required resources for performing risk management processes should be appointed, and new types of risk assessment points must be scheduled, which will be part of the risk management plan. Moreover, all the subsidiary risk plans must conform to the global project risk management plan.

The plan should provide guidance to the project management team in the use of risk management, both in the baseline schedule development and for the schedule updates. The plan development will serve to persuade the project management team to realize that managing risk is a formal procedure, with a regimented process to be used as the approach to a standardized plan [6]. As the PMI states, the risk appetite of stakeholders including the owner is recorded in the risk management plan. The appetite for risk is quantifiable and measurable. In some construction firms the risk management is not being taken into account seriously in the practice of the project management. There are many reasons for this such as the project managers often neglected or underestimated the project risks, and there are not special departments or special full-time staff to perform risk management duties.

\subsection{Risk identification}

Risk identification process involves identifying all the risks that the project may be exposed, their sources and their potential consequences regularly because the risks arise and develop throughout the life of the project as well as their characteristics. Therefore, risk identification is a continuous activity during the whole life cycle of the project. It's impossible to identify and manage all the risk in the construction projects. It can be a waste of time and counterproductive, so it's crucial to focus on the vital risks only [7]. All project stakeholders are encouraged to introduce a new individual or global risk sources into the risk management process. The PMI highlights project manager, project team members, project risk specialist, customers, external experts from application area, end user, operations managers, stakeholders, risk management experts as relevant stakeholders [8]. Identifying other stakeholders during this phase is recommended such as:

- Organizations or functions that provide decision making, funding, services related to the risk (including outsourced providers), policy (including regulators).

- Organizations/groups that will be impacted, directly or indirectly by the consequences should the risk occur but who do not fit into the categories. These are secondary stakeholders.

A more holistic approach to project management by incorporation of the departmental head at the primary stages of the project. Departmental heads need to be involved in order to promote higher levels of 
communication between departments and therefore reducing risks that are likely to occur [9]. There are numerous ways in which construction project risks can be categorized, for example in accordance with their occurrences in different construction stages, or in accordance with the nature of the risks [10]. Risks can be classified in several ways for different purpose as shown in table 1.

Table 6. Risk Identification Categories

\begin{tabular}{|c|c|}
\hline Risks Classification & Author \\
\hline $\begin{array}{l}\text { Investors risk, Contractor risk, Material supplier risk, Project managers risk, } \\
\text { Government risk, Other project stakeholders risk }\end{array}$ & (W. Lin, L. Yaqi, and W. Enmao) [11] \\
\hline $\begin{array}{l}\text { Preliminary design, Tender, Detailed design, Construction works, Financing } \\
\text { the investment }\end{array}$ & (N. Banaitiene and A. Banaitis ) [12] \\
\hline $\begin{array}{l}\text { Resources, Productivity, Design, Managerial, Payment, Client, Technical, } \\
\text { Subcontractors }\end{array}$ & (I. Dikmen, M.T. Birgonul, S. Han, 2007) [13] \\
\hline Project management, Engineering, Execution, Suppliers & (A. Nieto-Morote, F. Ruz-Vila, 2011) [14] \\
\hline $\begin{array}{l}\text { Construction safety related, Construction management, Engineering design, } \\
\text { Natural hazards, Socio and economic }\end{array}$ & (Y.C. Kuo, S.T. Lu, 2013) [15] \\
\hline $\begin{array}{l}\text { Quality related, Environment related, Safety related, Cost related, Time } \\
\text { related }\end{array}$ & (P.X.W. Zou, G. Zhang, J. Wang, 2007) [16] \\
\hline $\begin{array}{l}\text { Internal (Owner, Contractors, Subcontractors, Designers, Suppliers), } \\
\text { External (Social and Cult, Economic, Political, Natural, Others) }\end{array}$ & (S.M. El-Sayegh, 2008) [17] \\
\hline
\end{tabular}

\subsection{Qualitative risk analysis}

Qualitative risk analysis is responsible for the ranking of project risks. It is carried out throughout the project life cycle to ensure it's effectiveness by making the necessary changes. The ranking process can be conducted in many ways, organizations even possess their own special methods, but all the methods are built on the assessment of probability of occurrence and the impact on the project and combining them as primary factors as well as secondary factors such as the time allocated to the response to risks and the degree of project tolerance for these risks through limitations. The qualitative analysis is sufficient for rankordering risks. It allows sorting the risks from most to least important [5]. One of the most important steps of this process is risk categorization. Categorization can be conducted in several ways, finding common characteristics or root causes.

The Probability, impact matrix and the hierarchical charts are typical category-based tools for risk management. The matrix helps graphically to categorize the risks into groups in the dimensions of the probability of occurrence and impact. If the categorization is conducted by three dimensions, the twodimensional matrix is insufficient. Hierarchical charts display risks in two dimensions by the two axes, but the size of a graphical figure (usually disks, bubbles) represents a third dimension (e.g., acceptance level). This may lead to developing more effective risk responses by focusing attention and effort on the areas of highest risk exposure, or by designing standard risk responses to address groups of similar risks. Once a group of risks with the highest exposure is identified, greater attention can be paid to this category [8].

The guiding principle for the grouping of risks is based on risk breakdown structure (RBS) or work breakdown structure (WBS), and the aim of this process is to assign the groups to proper risk management plans and actions. The RBS generally focuses on the causes of risks handled by additional management attention, while the WBS is built on functional disciplines maintained by more leadership attention and organizational involvement [18]. The hierarchical structure very effective in construction practice, because risk factors are numerous, especially in large projects, and the ability of humans to evaluate several factors at the same time is very limited [10]. The priorities can be compared against targets or other criteria to measure risk management performance, to identify risks for which further analysis are needed, and to direct the development of action plans and the allocation of resources [19].

\subsection{Quantitative risk analysis}

The multi-dimensional concept of qualitative risk analysis underlies the phase perform quantitative risk analysis. On the one hand, this phase is optional, on the other hand, the analysis is numerical here. Quantitative risk analysis enables a reliable evaluation of risks. It is carried out on the risks identified in the 
qualitative analysis by conducting an impact analysis and numerical estimation for decision-making in case of doubt. The prerequisite of this assessment is the availability of relevant, quantifiable ratio scale data. The analysis is usually based on simulation that determines the effects of risks, sensitivity analysis, decision tree, or more rigorous statistical methods that provide further insight into project risk. The categorization of risks is a typical step for performing quantitative or qualitative risk analysis. The best way to deal with risks in a project is done frequently to ensure that the risks are addressed.

Frequently, the quantitative process is required by decision-maker stakeholders. Through undertaking the necessary activities for quantitative risk analysis, a newly updated risk register is achieved by introducing changes to the risk register obtained after qualitative analysis. The output of this phase is a list of risks that have been quantified in order of priority sorted by a combination of the probability analysis of the project, the probability of achieving the cost and time objectives, and the consequences [6]. Risk analysis is an essential step to help identify appropriate ways of dealing with risks. Organizations appreciate the benefits of risk management in construction projects, formal risk analysis and management techniques are rarely used due to lack of knowledge, inexperience, and doubts on appropriateness of these techniques for construction projects [12].

\subsection{Risk analysis verification}

It reviews the risk analysis output in order to define whether the listed risks are relevant to the organization's goals and could cause real threats. It's aimed to filter out all the risk not relevant to the organization's goals. This phase must be conducted by different employees in the organization who are not associated with the team who worked on the previous phase. The filtering technique provides useful resources for the real risk pretending to business objectives and saves the organization resources from working on risks not related to their goals [20].

\subsection{Plan risk responses}

The risk planning process aims to identify the appropriate methods and activities for the plan to address the risks identified in the risk register according to their priorities and relevance, in order to minimize their impacts. The responses include reviewing options, choosing strategies, and triggering actions. Properly selected responses are responsible for exploiting opportunities and reducing threats stemming from risks. The appropriate response can be selected from a set of strategies. If there are threatening effects, the project manager can escalate, avoid, transfer, mitigate, or accept it. If there are opportunities, very similar tools are to be employed: escalate, exploit, share, enhance, and accept. The organization should determine how they should be combined into its overall strategy, according to the extent to which it is prepared to accept or tolerate risk. Policy decisions such as this must be made at senior levels in the organization, not left to individual managers [19]. Ensuring that the cost of confrontation is proportional to the severity of the risk. The cost of confrontation should not be greater than the losses that occur if the risk occurs, in addition to the appropriate time of confrontation to avoid further losses.

After determining the appropriate strategy to address each risk, a number of changes are made to the risk register such as: specific risks, their clarity, the aspects of the project affected, their causes and the manner in which they may affect the project objectives, agreed risk response strategies, how to implement the chosen strategy, funding and time required to implement the selected strategies, contingency plans, standby plans where the specific response method is not appropriate, and contingency precautions. A part of documenting the decisions should include preparing a risk mitigation plan for those unresolved risks and acting on that plan. The risk mitigation plan might include just monitoring unresolved risks to ensure that they don't become a driver of productivity or delay [6]. According to risk management standard the stakeholders reach an agreement on which risk treatment is accepted. A detail treatment plan should be defined on how to be executed. Also, during this stage, reporting and communication are established to the stakeholders. The purpose is to share the knowledge obtained during the execution process [21]. In any project, the development and implementation of detailed action plans for reducing risks is the key to successful project risk management in practice [19]. 


\subsection{Risk plan experimentation}

It examines whether the risk planning performed in the previous step is accurate and comprehensive. It also checks if all risks are applicable to the organization and are correctly classified according to their impact and probability. It's aimed to prevent wasting resources throughout the implementation phase by assuring the validity of the risk [20].

\subsection{Implement risk responses}

It is implementing the most suitable and strict controls and procedures for the identified risks. The planned and agreed responses are executed here to decrease individual project threats, and to increase individual project opportunities. During the execution phase, risk control might require modifying the current execution plan, ending the risk or even starting a contingency plan if the current plan is found to be ineffective and requires starting from the beginning of the risk process if a new risk has been identified [22]. One of the major mistakes in this stage is that the risk management process is incomplete. The risk management process includes a throughout identification and analysis, risk plans (with lessons learned register, risk register, and risk report), but no effort and action are taken to finish it.

\subsection{Monitoring risks}

It is a tracking process for the implementation of the risk response plan. It is aimed to monitoring of residual risks and the identification of new risks and sources that could present after an action and should be communicate to the stakeholders to assess the effectiveness of risk management on all aspects of the project using the performance information obtained during the project implementation, which also enables to see if there is a follow-up that risk management procedures are in place, introducing the necessary changes to the project management plan and adjusting emergency reserves appropriately with the changes that occur. A proper tracking process results in decisions based on current information about project risks. Traditionally the data analysis consists of technical performance analysis and reserve analysis. The tools and techniques of monitoring are audits and meetings besides the data analysis. This phase is critical for formation of the lessons learned database [23].

\section{Suggested solutions to improve construction risk management}

Construction firms should establish a series of risk resistance mechanisms, include risk management planning process, risk management organizational mechanism, and risk management functional division. Moreover, the risk management department shall be established and assign a full-time experts and team who responsible for risk identification, control and management, and contribute to coordinate and solve the risk management problems existed among the relevant departments and the involved parties [4]. Construction projects include a widespread distribution of participants, complex specialty and huge information. Therefore, project participants need to know each other's information quickly and effectively, and project decision-makers need timely project information to take the right decision. The project risk information system shall be established, in order to reduce the cost of collection, exchange, and transmission of project information. Training is the keystone to any risk management plan. A risk management approach will most likely not be adopted or followed without a formal training effort. Training should not only take place at the beginning of the processes but should also include regular informational session to display any lessons learned, policy changes or identified leading practices. Also, refresher sessions are required to maintain employee's consciousness of risk management policies and procedures and assure that organizations are committed to risk management. Implementing a standard process is very crucial to ensure consistency and avoid duplication of reporting. The project team including the project manager selects the sufficiently important project risks and gives the appropriate response. The responsibility for responding to risks when they occur for only one person in order to ensure focus and not to be distracted and neglect. Some project managers are trying to manage all risks themselves. Therefore, Identify and hire risk owners with the experience and ability to develop and execute risk response plans effectively and efficiently. 


\section{Conclusion}

The organizations are required to deal with risks carefully by adopting scientific methods to face them and ensure the success of their projects, and this can only be achieved by following the risk management approach in the project. Effective risk management, especially in the construction industry, helps to execute projects correctly, which reflects on project success positively, and brings benefits to all parties of the project. Keeping in mind that managing risks effectively does not mean avoiding it, rather recognizing it correctly and knowing all the opportunities and risks associated with it. In this paper, an extension of standard risk management had been introduced from the construction perspective, which includes two more processes that are risk analysis verification and risk plan experimentation, in order to implement the risk management smoothly and achieve the project objectives. Furthermore, some suggestions had been highlighted to improve construction risk management and execute risk management system effectively and efficiently.

\section{References}

[1] M. Ebrahimia, M. Asadia, H. Akbarib, A. Shakeric, Petrochemical industries and the opportunities provided by effective risk management; A case study, (2012).

[2] R.M. Choudhry, K. Iqbal, Identification of risk management system in construction industry in Pakistan, Journal of Management in Engineering, vol 29, no. 1 (2013) pp. 42-49. https://doi.org/10.1061/(ASCE)ME.1943-5479.0000122.

[3] J. Abdulaziz M., T.C. Haupt, Major construction risk factors considered by general contractors in Qatar, vol 13, no. 1 (2015) https://doi.org/doi.org/10.1108/JEDT-03-2014-0012.

[4] Z.Y. Zhao, L.L. Duan, An integrated risk management model for construction projects, PICMET: Portland International Center for Management of Engineering and Technology, Proceedings, no. c (2008) pp. 1389-1394. https://doi.org/10.1109/PICMET.2008.4599751.

[5] T. Kendrick, Identifying and managing project risk : essential tools for failure-proofing your project. American Management Association, 2003.

[6] S. Mubarak, Construction Project Scheduling and control, Second Ed. John Wiley \& Sons, Inc., Hoboken, New Jersey, 2010.

[7] S.M. El-Sayegh, M.H. Mansour, Risk assessment and allocation in highway construction projects in the UAE, Journal of Management in Engineering, vol 31, no. 6 (2015) https://doi.org/10.1061/(ASCE)ME.1943-5479.0000365.

[8] Project Management Institute, Project Management Book of Knowledge, Sixth Ed. Newtown Square, Pennsylvania 19073-3299 USA, 2017.

[9] B. Kayis et al., IRMAS - Development of a risk management tool for collaborative multi-site, multi-partner new product development projects, Journal of Manufacturing Technology Management, vol 18, no. 4 (2007) pp. 387-414. https://doi.org/10.1108/17410380710743770.

[10] H. Zhi, Risk management for overseas construction projects, International Journal of Project Management, vol 13, no. 4 (1995) pp. 231-237. https://doi.org/10.1016/0263-7863(95)00015-I.

[11] W. Lin, L. Yaqi, W. Enmao, Research on Risk Management of Railway Engineering Construction, Systems Engineering Procedia, vol 1 (2011) pp. 174-180. https://doi.org/10.1016/j.sepro.2011.08.029.

[12] N. Banaitiene, A. Banaitis, Risk management in construction projects." Risk Management-Current Issues and Challenges", Procedia Engineering, (2012) pp. 429-448. https://doi.org/10.5772/51460.

[13] I. Dikmen, M.T. Birgonul, S. Han, Using fuzzy risk assessment to rate cost overrun risk in international construction projects, International Journal of Project Management, vol 25, no. 5 (2007) pp. 494-505. https://doi.org/10.1016/j.ijproman.2006.12.002.

[14] A. Nieto-Morote, F. Ruz-Vila, A fuzzy approach to construction project risk assessment, International Journal of Project Management, vol 29, no. 2 (2011) pp. 220-231. https://doi.org/10.1016/j.jproman.2010.02.002.

[15] Y.C. Kuo, S.T. Lu, Using fuzzy multiple criteria decision making approach to enhance risk assessment for metropolitan construction projects, International Journal of Project Management, vol 31, no. 4 (2013) pp. 602-614. https://doi.org/10.1016/j.ijproman.2012.10.003.

[16] P.X.W. Zou, G. Zhang, J. Wang, Understanding the key risks in construction projects in China, International Journal of Project Management, vol 25, no. 6 (2007) pp. 601-614. https://doi.org/10.1016/j.jproman.2007.03.001.

[17] S.M. El-Sayegh, Risk assessment and allocation in the UAE construction industry, International Journal of Project Management, vol 26, no. 4 (2008) pp. 431-438. https://doi.org/10.1016/j.ijproman.2007.07.004.

[18] M. Bissonette, Project risk management : a practical implementation approach. Project Management Institute, 2016.

[19] C. Dale F., G. Stephen, R. Geoffrey, W. Phil, Project Risk Management Guidelines: Managing Risk in Large Projects and Complex Procurements. Chichester: J. Wiley, 2005.

[20] S. Al-Hawari, F. Thabtah, L. Karadsheh, W.M. Hadi, A risk management model for project execution, Information Management in the Modern Organizations: Trends and Solutions - Proceedings of the 9th International Business Information Management Association Conference, vol 1-2 (2008) pp. 887-893.

[21] Institute of Risk Management, A Risk Management Standard. London, 2002.

[22] J. Perera, J. Holsomback, An integrated risk management tool and process, IEEE Aerospace Conference Proceedings, (2005) pp. 129-136. https://doi.org/10.1109/AERO.2005.1559306.

[23] A.E. Yildiz, I. Dikmen, M.T. Birgonul, K. Ercoskun, S. Alten, A knowledge-based risk mapping tool for cost estimation of international construction projects, Automation in Construction, vol 43 (2014) pp. 144-155. https://doi.org/10.1016/j.autcon.2014.03.010. 